\title{
Automation of play: theorizing self- playing games and post-human ludic agents
}

Sonia Fizek

This is the accepted manuscript of an article published in Journal of Gaming and Virtual Worlds available from: DOI: https://doi.org/10.1386/jgvw.10.3.203_1 


\title{
Automation of play: Theorizing self-playing games and post-
}

\section{human ludic agents}

Sonia Fizek

\begin{abstract}
This article offers a critical reflection on automation of play and its significance for the theoretical enquiries into digital games and play. Automation has become an ever more noticeable phenomenon in the domain of video games, expressed by self-playing game worlds, self-acting characters, and non-human agents traversing multiplayer spaces. On the following pages, the author explores various instances of automated non-human play and proposes a post-human theoretical lens, which may help to create a new framework for the understanding of video games, renegotiate the current theories of interaction prevalent in game studies, and rethink the relationship between human players and digital games.
\end{abstract}

\section{Keywords}

aesthetic of video games

theory of video games

automata

automation of play

self-playing games

post-humanism 


\section{Automated state of play}

The modern understanding of the term automation (Greek: autómatos, self-moving), going back to sixteenth century, denotes a machine with a self-contained principle of motion (Truitt 2015: 2). A digital computer, with a motherboard at its heart, is in many ways precisely such a machine. Thus, most games, staged within the medium of the computer, involve some level of automation, such as calculating gathered props, lost lives, or the player's proximity to an enemy NPC. Unlike in board games, where all such computation needs to be done manually by the human player, in a digital game most of the processes are automated and hidden from the player's view. This type of automation is well known to an average gamer. What is much more mesmerizing is the sort of automation reflected in the representational layer of the game, bringing the 'aesthetics of agency and control (or the loss of these)' (Giddings 2005) to the forefront. Many recent examples I will draw upon on the pages to follow tend to partially or entirely automate those parts of gameplay, which are usually performed by humans. Think about movement-simulating bots of Pokémon Go, 'self-acting' non-human agents or the socalled non-player characters (NPCs), or game worlds changing independently of the human player's actions in one of Fallout 4 mods.

Despite this perceived agency, 'liveliness' or 'smartness' of many ludic systems, the understanding of what digital games are and what it means to play them, usually tends to fall back on anthropocentric narratives, placing the human player as a necessary central component of the agential experience. ${ }^{1}$ The proverbial state of play in how digital games are perceived and defined seems to be revealing a very binary world-view: human versus

\footnotetext{
${ }^{1}$ With a few examples including a contribution on zero-player games by Björk and Juul (2012).
} 
computer, organic versus the inorganic (Haraway [1991] 2000), active versus passive or player versus game.

On the following pages, I would like to propose to rethink digital games and play, shying away from the purely anthropocentric perspective according to which humans are the active subjects and the game a mouldable object of human desire. It is precisely this alleged subject-object boundary that is transgressed in digital game play (Giddings 2005). After all, video games are actions, not only of the human players but equally so of the machines, to emphasize with Galloway (2006). By their very nature, they break down the subject-object, organic-inorganic and player-game dichotomies. They constitute ludic ensembles, 'inter-species assemblages' (Dyer-Witheford 2015) or 'biologicaltechnological-informational' collages (Stasieńko 2017: 44).

My aim in this introductory article is to reflect video games, looking at such paradoxical examples as self-playing games, 'idling' or automated gameplay modes. I will start with a brief narrative on the fascinating past of automata in order to historicize automation of play beyond the digital playgrounds of the late twentieth and early twentyfirst centuries. The Mechanical Turk (1770), an android displayed at the courts of Europe, will serve here as a point of departure and a bridge in the post-human ludic story told on the pages to follow. I will then 'zoom in' to a few examples of video games with automated gameplay components, and follow up with a post-human theoretical lens, which may be helpful in reflecting the phenomenon of play automation in particular, and digital gameplay in general. This critical inquiry into automated play is also an attempt to offer an alternative to interactivity-centred discourse so prevalent since the beginnings of video game studies. 


\section{Self-playing automata of Enlightenment and algorithms of today}

The dreams of devising self-acting or self-playing machines (in a broad understanding of the term, also encompassing musical play) are much older than digital computers. They may be traced back to Enlightenment (Voskuhl 2013), if not Antiquity (Truitt 2015). ${ }^{2}$ Automata and autonomous or semi-autonomous machines, mimicking various actions such as moving, singing, writing or playing - have been the subject of human curiosity and artistry for thousands of years. Whether hydraulic, pneumatic, mechanical, electrical or digital (de Valk 2016), they lured with a promise to emulate, challenge and ultimately excel the human capacity.

Perhaps the most recognized games-related experiment of this kind in the western tradition, points towards the late eighteenth-century invention - The Mechanical Turk, also known as the Automaton Chess Player, an anthropomorphic life-sized figure of a player, whose mechanical arms were put to motion by a clockwork mechanism. Wolfgang von Kempelen, a civil servant and an imperial councillor, embarked upon the quest to design the Turk in 1769 in order to impress the Empress of Austria-Hungary, Maria Theresa. He did not have much time as other 'magicians' visited the court and presented their latest experiments on magnetism ${ }^{3}$ or mechanical writing. ${ }^{4} \mathrm{He}$ completed the Chess Player in six months and in 1770 the Turk played its first game against the human opponent. At first, the inventor himself allegedly refused to make a fully open public exhibition of it, an act that has been ascribed to his true genius indifferent to

\footnotetext{
${ }^{2}$ Automata were already built in Antiquity and described in the treatises of Hero of Alexandria, which alluded to self-moving water clocks, automatic theatres and many other self-moving hydraulic wonders (Riskin 2003; Truitt 2015: 4).

${ }^{3}$ François Pelletier, an illusionist, allegedly visited the court to present his experiments on magnetism.

4 The 'Miracle Writing Machine' (Allesschreibende Wundermaschine) was built by the German mechanic Friedrich von Knaus (1724-89), who presented it in 1760 to the empress Maria Theresa in Vienna.
} 
popular favour. He even considered dismantling the Automaton to pieces, much like the ingenious forger Trurl, a pivotal fictitious figure re-appearing in many short stories by Stanislaw Lem. In 'The Great Spanking' (1983), Trurl allegedly devised an intelligent wish-fulfilling machine, which could make an indistinguishable copy of himself. When almost disguised by his opponent as an imposter, Trurl disassembled his own creation to pieces, leaving no trace of it but the stories and praising accounts of its existence. Von Kempelen decided to keep the Chess Player and kindle the stories of its artisanal genius for generations to come.

The Automaton had been travelling the globe for 84 years, outliving its inventor by a few decades and defeating human opponents, amongst them Napoleon Bonaparte, Benjamin Franklin and Charles Babbage. In 1819 it reached London's Spring Gardens, where it was publicly exhibited. An anonymous Oxford graduate observer, in a 32-page long account of the encounter, described the figure's apparition and mechanism, and questioned the possibility of it displaying the intelligence of a reasoning agent. Not being able to find the true source of simulation, he had come to the conclusion that the seeming impossibility had indeed been surmounted by the Automaton Chess Player:

\footnotetext{
To construct an arm and hand capable of performing the ordinary functions of those parts, would be of itself sufficient to secure the reputation of an artist; but to make the same arm and hand almost counterparts of living members in a reasoning agent, displays a power of invention as bold and original, as any that has yet been exhibited to the world.
}

(Observations on the Automaton Chess Player 1819) 
The Turk, as an oriental self-playing figure of a sorcerer placed at a robust wooden desk with a chessboard, in addition strengthened the audience's perception of it as an unrevealed mystery foreign to their cultural territory. Already in the medieval period '[...] Latin Christians associated automata with Arab, Greek, and Mongol courts and saw them [...] as the products of foreign knowledge and exotic materials' (Truitt 2015: 19). In the end, The Turk, instead of being a mysteriously devised intelligent machine, turned out to be an elaborate hoax; an illusion played upon generations of audiences and chess players, defeated not by a machine, but a human skilfully hidden inside the wooden desk and operating the mechanical arms. Despite being a disappointment, the Turk nevertheless became a symbolic exemplification of dreams of devising intelligent machines automating human physical and cognitive processes. It reflected the desire to '[...] imitate and expand the human mind, which has been the main project throughout the history of mechanization of the mind pursued by many notable figures including Pascal, Leibniz, Babbage, Wiener, and Turing' (Aytes 2011).

Automata, androids and machines had also become the subjects of many literary works of the late eighteenth century and continued to feed the imagination of modern science-fiction authors, bringing to life such figures as Frankenstein, among many others. The Turk, for instance, became a source of inspiration for a German writer Johann Paul Friedrich Richter (later known as Jean Paul), who explored the boundaries between humans and machines. In a satirical-philosophical text 'Humans are machines of the angels' ('Menschen sind Maschinen der Engel', 1795) '[h]e talks about an angel who built chess-playing machines, for the sake of "curiosity and pleasure rather than for utility"” (Voskuhl 2013): 
Ein Engel verfertigte auch, wiewol mehr der Seltenheit und des Vergnügens als des Nuzens wegen, herliche Schachmaschinen [...]

(Richter 1795)

And this crucial polarity between utility and playful curiosity brings me to Google's algorithmic Go player, the most current descendant of the Mechanical Turk. On 9 March 2016 the algorithm was presented at the Google DeepMind Challenge, a public Go match staging a human and a machine, the first event of that kind since the acclaimed 1997 chess match between Deep Blue and Garry Kasparov. Lee Sedol, the world's second best Go player, also referred to as 'The Strong Stone', played against the algorithm devised by a group of machine-learning scientists at the Google's Deep Blue company. After seven days, the South Korean grandmaster of Go left the scene defeated by the AlphaGo 4-1.

AlphaGo is claimed to be a multipurpose general algorithm tested within the game's framework but developed with a broader scope and the aim to become adaptable for numerous objectives, able to learn automatically from scratch rather than being preprogrammed. It has raised human curiosity but is made to be applied rather than merely displayed for entertainment. AlphaGo has been learning from the behavioural patterns of 100.000 amateur human Go players, further replaying itself 30 million times and becoming stronger with every iteration (BBC Newsnight 2016). This version of the algorithm was a big step in AI simulating human cognitive capacities, able to win a game, whose complexity far exceeds chess and is said to have more configurations than there are known atoms in the universe. The version, which in 2016 outplayed Lee Sedol, the winner of eighteenth $18^{\mathrm{t}}$ international Go titles, has been recently challenged by an 
even stronger opponent, its second successor algorithm trained by random self-play only, this time with no initial human input. AlphaGo Zero beat AlphaGo Lee 100 to 0 (Deepmind). Google's team published their findings in Nature, proclaiming AlphaGo Zero as an algorithm achieving 'superhuman performance' (Silver et al. 2017). This statement, even when taken with a pinch of salt, is particularly interesting, taking into account the long history of automata, robots and artificial life. Historians of science have noticed a continuity of thought (Voskuhl 2013) connecting the automata of Antiquity, Middle Ages and Enlightenment (Truitt 2015) with the robots of cybernetic modernity or the algorithms of post-modernity, although the first ones were devised in much different pre-industrial times and presented to a very distant audience. Google's latest Go experiments bring to mind John von Neumann's visions of self-reproducing machines programmed to build themselves without the need of a human intervention (von Neumann 1966). AlphaGo Zero is not a 'slavish type of machine' (Cohen 1967: 120-21), like chess-playing IBM's Deep Blue (1997) or Arthur Lee Samuel's Checkers-Playing Program (1959), both of which outplayed their human opponents by sheer force of calculation and still required the programmer to lay down the general strategy in advance (Cohen 1967: 120-21). AlphaGo and AlphaGo Zero epitomise some of Licklider's (1960) speculations that machines may possibly outdo the human brain and dominate in the future.

But the story of self-playing AlphaGo Zero has also another fascinating dimension. The algorithm, once decoupled from learning based on human performance, developed its own strategies, differing from all the known moves played by humans in 
the last 2.500 years; thus encouraging human players to see the Go board with new eyes and learn from the unusual repertoire of AlphaGo's moves.

\section{Mods, bots and non-human ludic agents}

To some degree, such a playful post-human engagement between humans and algorithms - whether competitive or collaborative - rests at the base of computer games. Due to their technological nature, games reflect 'the distributions and delegations of agency between technologies and players in the act of playing' (Giddings 2005). The current deployment of bots and various autoplay modes further amplify the imaginary of non-human agentiality. Let us have a look at a few illustrative examples.

In Sim Settlements (Livingston 2017), ${ }^{5}$ one of the most recent Fallout 4 (2015) mods, NPCs build their own housing, plant their own crops, even work in shops they themselves construct. The human player is welcome to the city-building algorithmic spectacle as a by-stander and a delegating agent. The NPCs do not need to be micromanaged by the player. Instead, they metaphorically take matters in their own hands, in a similar way to the delegated gameplay model known from god-simulation genres. In this way, the game world acquires a life-like dimension from the perspective of the human player. As one of the mod's users emphasizes:

The buildings your settlers construct aren't cookie-cutter affairs: they're all a bit different, right down to the clutter that eventually appears inside them. This means just about every house and store your NPCs build will look unique. I was

\footnotetext{
${ }^{5}$ Settlements building themselves: https://www.youtube.com/watch?v=67Dj4m_uj5s.
} 
oddly pleased to see my companion Curie build herself a home out of a trailer rather than a wood or tin shack like everyone else had done.

(Livingston 2017)

The mod automatically assigns citizen NPCs to plots pre-selected by the player (e.g. farming, residential or industrial plots). Automation of gameplay has become a common practice in the modding community. A lot of other games come with mods based on progressive automation. One of them is Minecraft, in which the player can excavate the game's environment with the help of automatic miners, set up farms that will plant and harvest crops, or use crafting machines, which will automatically craft the contents of the inventory.

Within an established genre of massively multiplayer online role-playing games, modding has become a debatable practice. Many players tend to use the so-called bots and macros (third-party software) to partially automate gameplay, deskill the players (De Paoli 2013) and alleviate the repetitiveness of tedious tasks necessary in order to level up the characters more efficiently. In most cases the practice is undesired by the game developers. Blizzard banns the unfair use of smart bots automating the gameplay of World of Warcraft:

We've recently taken action against a large number of World of Warcraft accounts that were found to be using third-party programs that automate gameplay, known as 'bots.' We're committed to providing an equal and fair playing field for everyone in World of Warcraft, and will continue to take action 
against those found in violation of our Terms of Use. Cheating of any form will not be tolerated.

(Blizzard's statement 2015)

A similar reaction has affected gameplay automation enthusiasts in Pokémon Go, a multiplayer augmented reality game, in which the players move in the real world in order to locate and capture virtual Pokémon creatures, visible on the screens of their mobile devices. Some players automate this tedious collection process, by using bots and other third-party software to send off alleged GPS locations, while not moving an inch in the physical world. Niantic, the game's developer, has been actively finding ways to eliminate this type of subversive gameplay or cheating. Players seem to delegate the act of play onto to the algorithms for numerous reasons. For efficiency. For time saving. For fun.

\section{Idling and self-playing games}

Gameplay automation has also defined an entire casual game genre. In the so-called incremental ('idle') games, also referred to as passive, self-playing or clicker games, there is minimal active engagement required from the player in order for the game to progress. ${ }^{6}$ The initial stages of most idle games (e.g. AdVenture Capitalist, 2015; Cookie Clicker, 2013; Universal Paperclips, 2017) start with the player performing a simple task of clicking in order to gain more in-game currency (e.g. logs, coins, cookies, etc.), which in turn allows them to acquire items or skills that automate most of the gameplay in the

\footnotetext{
${ }^{6}$ I have discussed self-play within the context of idle games more extensively in the following article: 'Interpassivity and the joy of delegated play in idle games' (Fizek 2018a).
} 
future. As the game unfolds incrementally, more options emerge and more tasks are automated. Idle games are semi-automated 'ongoing, never-ending affairs' (Bogost 2010).

In other words, in idle games the player's constant participation is not a necessary condition for play to take place. Play emerges as a substitutive act - the player, represented by the automatic clicker algorithms, may take absence from the game. In the early stages of Cookie Clicker, for instance, one may delegate the cumbersome task of cookie production to 'Cursors' and 'Grandmas'. Having earned enough cookie currency, the player then may proceed to set up 'Farms', 'Mines', 'Temples' and 'Wizard Towers' to further multiply the cookie realm. Every now and then, the player comes back to the game in order to unlock further upgrades, check statistics and browse through an expanding collection of achievements. The random 'golden cookie' boost acts as an encouragement to come back to the game in order to increase the cookie meter and manually click alongside the automatically proceeding gameplay. The game may slow down without the human presence, but it will not come to a complete halt. Many players flip between the tabs of the Internet browser, constantly going in and out of the game. This intermittent interaction pattern, emerging as a result of this sort of delegated play, defines the active moments between automated gameplay sessions. The gameplay is reversed, as if the 'load' screen was the actual game and the gameplay a moment to 'wind up' or 'load' the game. 


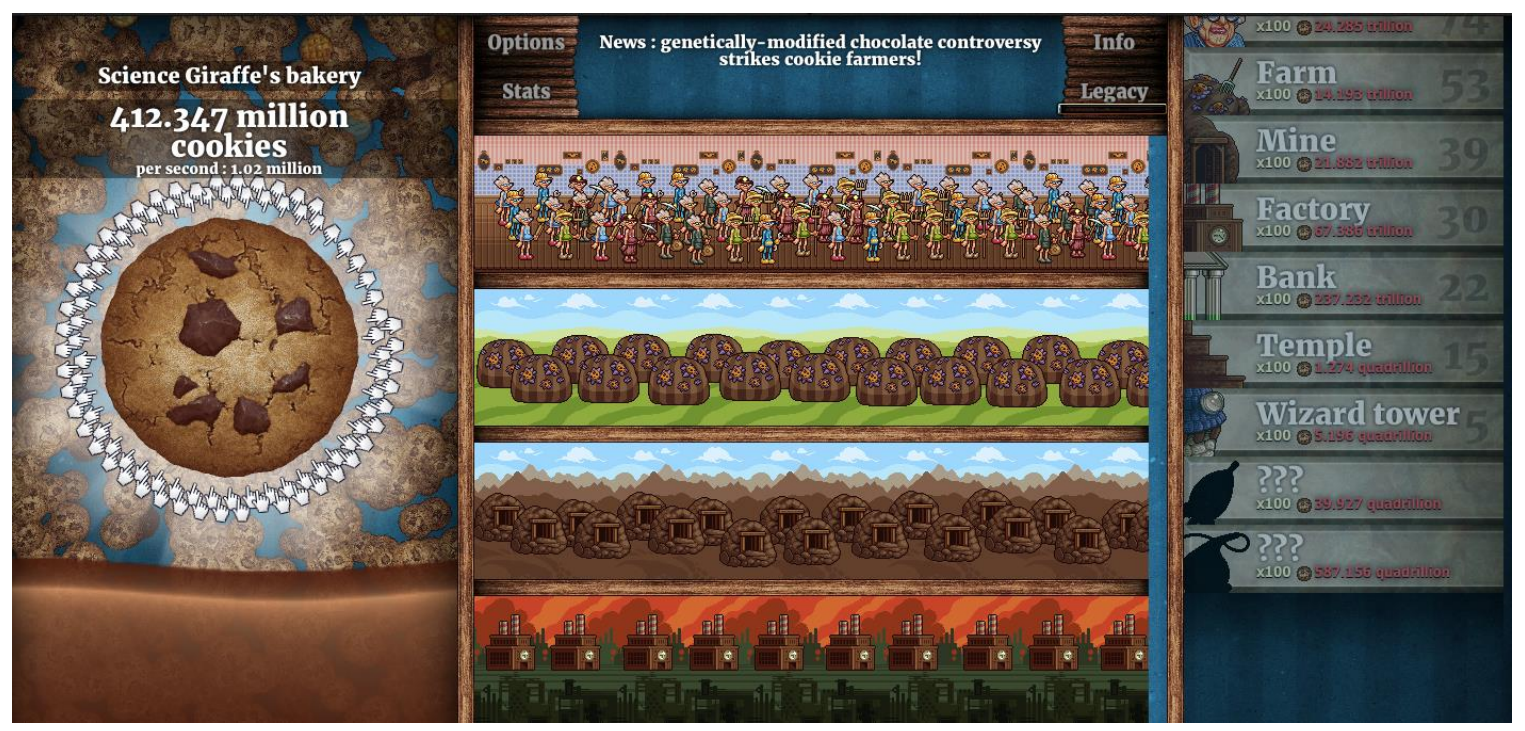

Figure 1: Cookie Clicker (2013)

This play pattern brings to mind the nineteenth-century street barrel organs, played by rotating a handle in a cyclical motion, and thus delegating the actual task of playing the organs to the 'programmed' cylinder. Perhaps on some level, I could risk a comparison of the tasks of an idle gamer to those performed by barrel grinders. After all, both consist in delegating the otherwise highly absorbing, oftentimes tedious and complex activity of play to a machine, which needs to be 'ground' from time to time in order to keep playing.

Another fascinating example of automated play may be observed in Everything (2017). In David OReilly's open-ended simulation, the player can do everything and at the same time does not have to do anything at all. On the one hand, the game invites the player to a sandbox-like exploration of its universe, giving them the possibility to get into the shoes of every creature possible: 
I am Rock Planet, small and grey. Soon I am Sun, and then I am Lenticular Galaxy. Things seem a little too ordinary, so I pull up a menu and transform my galaxy into a Woolly Mammoth. With another button I multiply them. I am mammoths, in the vacuum of space.

(Bogost 2017)

On the other, if left unattended, the game starts playing automatically:

One might let Everything play in the background while doing other things, letting it be an ambient aquarium of universes.

(Brewster 2017)

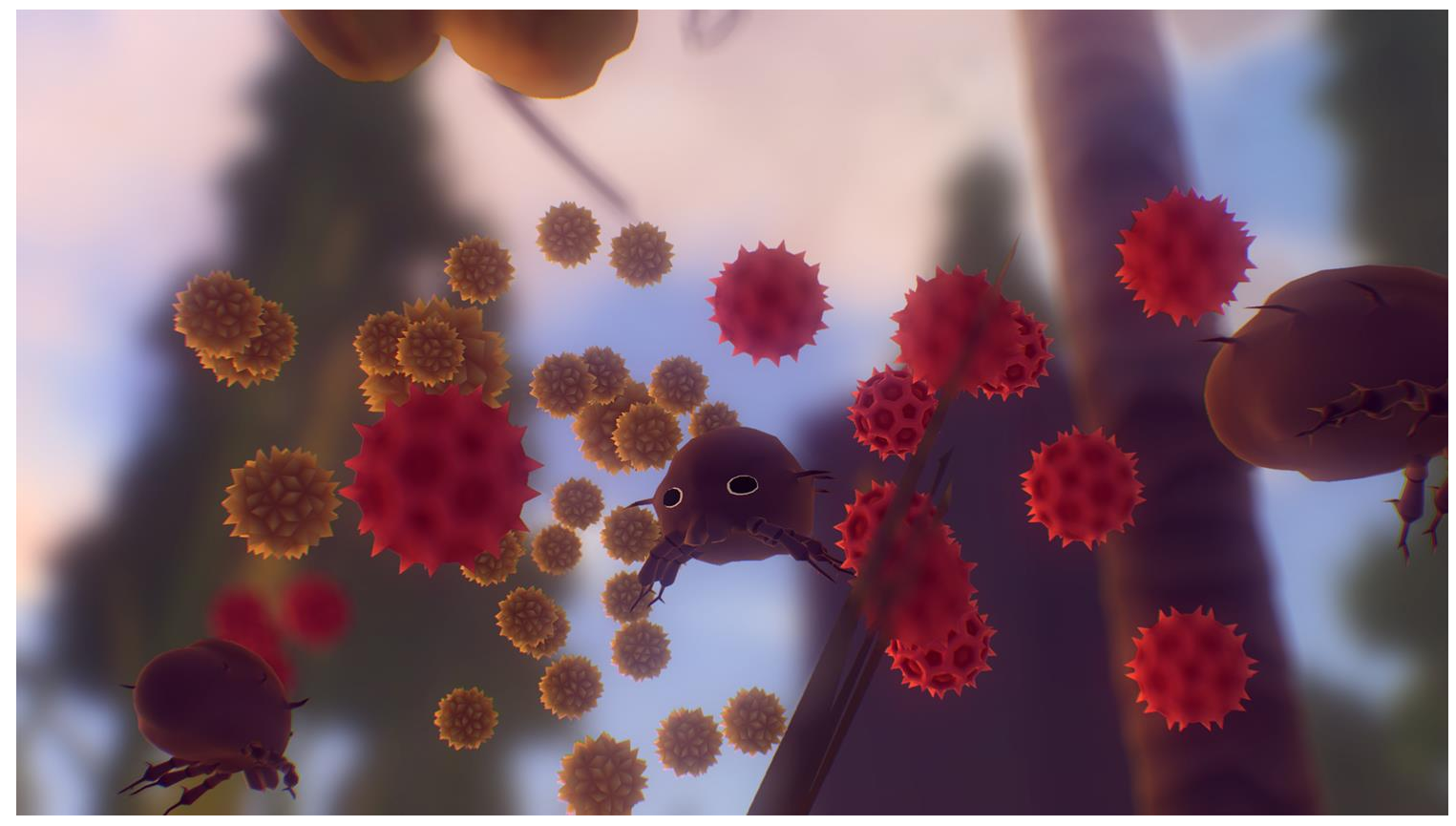

Figure 2: Everything (2017) 
And finally, Emissaries (2015-17), an obscure art simulation trilogy by a digital artist Ian Cheng, described by the author as a video game that plays itself. It was originally exhibited in 2017 in MoMA PS1 in New York and simultaneously online on the Twitch.tv gaming platform. It is important to remember that Emissaries is not an animation (although it may look like one in a museum hallway), but a series of simulations rendering live on the screen. 'The works are comprised of computergenerated simulations like those used in predictive technologies for complex scenarios such as climate change or elections', we can read on MoMA's website. To create the simulations Cheng used a popular video game development engine Unity, which allowed him to programme the physical characteristics of the world. It also contains various types of AI assigned to the characters and entities of the world, competing with one another.

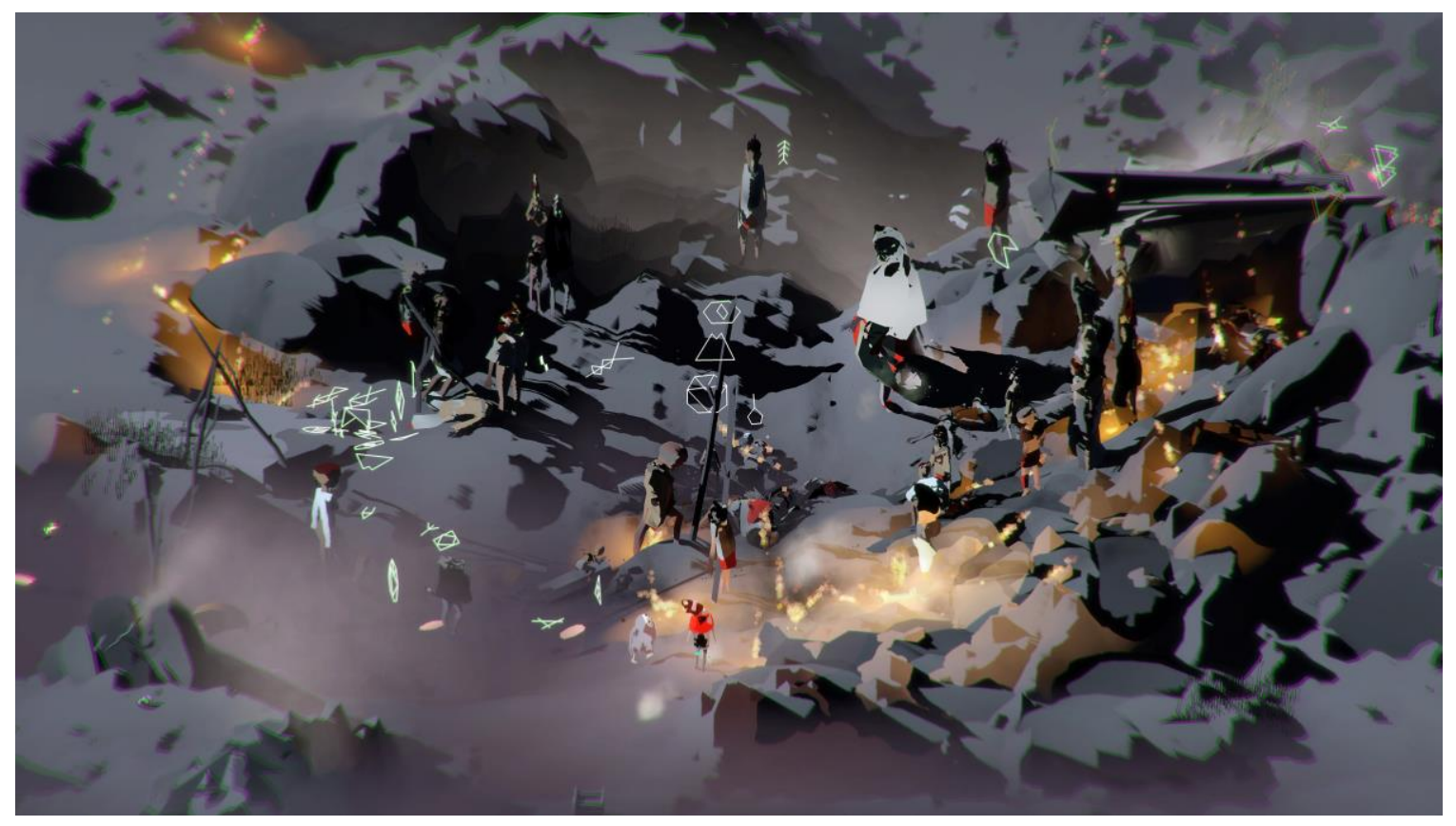

Figure 3: Emissaries (2017) 
All the instances of play mentioned above not only subvert the contemporary understanding of games as solely interactive media, but also reformulate the usually centric role of the player. When the game plays itself, the performative character of play is shifted towards the game itself. In such cases, the game becomes a self-governing homeostatic system, a retroactive machine acting and reacting upon itself.

\section{Post-human play: Rethinking anthropocentric rules of the game}

Automation of play, in its manifold variations, has become a visible part of the ludic landscape. Players seem to find it quite an astounding experience, especially, if it involves representations of human-like figures, who virtually embody the self-acting algorithms, producing an illusion of a living agent in a dynamically responding world. The fascination with life-like capacities of virtual spaces resounds in the following words of the player:

I can't remember when I first saw AI picking fights with each other [...] [but] the first time it happened, it was a minor moment of joy. Not because the enemy of my enemy is my friend, $[\ldots]$ but because it meant the game world wasn't all about me.

(Rossignol 2012)

The above words expressing a moment of ludic epiphany ('the game world wasn't all about me') open a much-needed discussion on the non-player centric perception of digital play, and the part of the human player within it. Humans are usually depicted as sole meaningful agents, deriving pleasure from control over the game. In most digital games, 
the role of the human player is to actively participate in gameplay, and that of the machine to enable, sustain and facilitate play; record its progress and communicate the outcome to the player. In many of the examples mentioned above, the human becomes a witness to the system's agency, and a delegator of play onto the algorithms (bots, mods, ludic system).

At a first glimpse, automation of play and self-acting AI seem like problematic parts of a puzzling paradox. After all, games have been primarily understood as objects to be actively engaged with, conflicts to be resolved and meaningful actions to be taken (Huizinga [1938] 1992; Caillois [1958] 2001; Crawford 1982; Juul 2003; Salen and Zimmerman 2003). They are supposed to be ergodic, requiring a non-trivial effort from their participants, who in turn need to actively interpret the activity as a game for it to be considered one (Aarseth 1997; Aarseth and Calleja 2015). If anything else, games have been described as inherently interactive (Crawford 1984; Ermi and Mäyrä 2005), and oftentimes in contrast to non-interactive or less interactive media such as films or books, however problematic such oppositions may be. In other words, most digital games, staged in the medium of a computer, could be described as 'explicitly participational' (Manovich 2001: 71). Of course all the above assumptions are made with regard to human players.

This paradox, however, does not have to express any conflict of interests. It rather opens the category of agency towards non-human entities. Control over the game becomes an act of negotiation between human players and non-human actors, defining what I refer to as post-human play. A post-human (Braidotti 2013; Ferrando 2013, 2018) tone resounds also in Alexander Galloway's early definition of digital games, according 
to which they are not only the actions of human operators but equally so, those of machines (Galloway 2006). Even more so, of machines, which do not always act in response to human players, but independently of them in the so-called 'ambience acts' of the machine - the moments when the digital game plays itself while waiting for the player to return and continue where they left off (Galloway 2006). As we have seen in a variety of examples discussed in the previous sections, the agential dimension of the machine becomes an ever more present part of gameplay. Therefore, it is crucial to take a closer look at such conceptions of agency, which take into account the interplay between the machine and the (human) player (Mukherjee 2008: 235).

By bringing automation of play into the centre of discussion, I am following in the footsteps of non-human dimension of digital play, the subject of an extensive debate opened by Seth Giddings a decade ago, when he proposed to recognize technological agency and shy away from the anthropocentric assumption that agency resides solely in the human (Giddings 2005). Video games as instances of everyday technoculture, as such operate within the premises of digitality, technology, simulations and software. The digital and networked nature of the computer calls for a decentralized understanding of the player as an active agent. Post-humanist thought seems to be offering a promising perspective for games research in this respect. The subjectivity of the player is redistributed during gameplay into a post-human network of human and non-human bodies and agentialities (Stasieńko 2017). The idea of who the player is, is simultaneously shaped and expanded by the game itself - it rests between a technological interface and a represented fictional world (Keogh 2014). 
It is an eye-opening act to look at the world from the perspective of a thing as Ian Bogost notices in Alien Phenomenology (2012). It is equally fascinating, if not necessary in order to understand digital play, to move beyond the human and look at the phenomena of gaming from the point of view of the game instead (Wark 2009: 223). The very fact that games entail AI, procedural generation, complex agential relations between the player and the avatar, mean that strict divisions into subject and object, activity and passivity need to be rethought. After all, the game's script is put into motion not only by the sheer agency of the human player but also by AI scripts (Stasieńko 2017: 42) and the hardware.

Technology is an inseparable part of being human. It is more than a mere tool to achieve goals. This perspective of human-technological interconnectedness, named by Katherine Hayles as technogenesis (Hayles 2011), manifests itself in the way digital games operate as human-non-human ludic entanglements, embodying the agential role of the machine. The digitality of computer games, as I have emphasized with Galloway and Giddings amongst others, turns them into almost unquestionable examples of technogenesis and post-anthropocentrism (Braidotti 2013). The examples of self-acting and self-playing AI, which I have drown upon in the previous section, make the technocultural, technogentic and post-human dimensions even more pronounced. It seems that digital games by their very nature break down the subject-object, organicinorganic and player-game dichotomies. They constitute ludic ensembles, 'inter-species assemblages' (Dyer-Witheford: 2015) or 'biological-technological-informational' collages (Stasieńko 2017: 44). 


\section{Towards a post-human aesthetic of video games and play}

Automation of play is a growing phenomenon, but most importantly a complex one. It goes hand in hand with AI and encompasses a wide range of differing examples, from self-learning Go algorithms, self-changing game worlds, bot-driven gameplay to 'idling'. Although all of them highlight a post-human understanding of digital games, they differ substantially not only in terms of the specific algorithms used but more importantly in terms of varied contexts of their existence, and the place of the human within this posthuman ludic assemblage.

Some algorithmic actors seem to be a twenty-first-century interpretation and continuation of the Enlightenment android motif. Such algorithms are displayed mainly for human amusement. Others could be seen as cognates of spinning machines, steam engines and punch cards. The practices of autocrafting in Minecraft, botting in multiplayer online games, and 'idling' - discussed in the previous section - all bring to mind the processes of mechanisation of labour and work management. These mods are employed by the players for the sake of utility rather than sheer pleasure to emphasize with Jean Paul, already mentioned in this article. More future work needs to be undertaken on the AI-driven automation aspect in games and virtual environments. How do we interact with self-playing systems? Do algorithms play? Can we even talk of a game, if it does not involve active human participation? These are just some of the daunting questions.

Perhaps the automation of play marks an arrival of a new kind of aesthetic of video games and digital play; one that would see agency and action as qualities distributed between humans, AI and hardware. Some important questions arise: how 
should we judge the beauty of an automated game, the perfectly efficient automated speed run, the algorithm-inspired new move combination in Go, an incrementally growing semi-automated game system? Perhaps a post-human aesthetic could involve a combination of procedural artistry of the system and the human spectatorship of it.

Post-humanism could serve here as a metaphorical angle, a framework of thought, which allows to see all the multiplicities of play in digital environments or the so-called performative multiplicities (Jayemanne 2017). In other words still, by focusing on the automation of play through a post-humanist lens I do not claim a game world with no human players or aim to assign meaning and intentionality to an algorithm. Instead, I propose to open the video game category to different human-non-human constellations of play, human and machine acts, and all the experiments, which may be described as post-human play; post-human in the sense of non-dualistic and non-anthropocentric (Ferrando 2018). Such a perspective shift would allow us to reinvestigate the subjectobject divide and perhaps think of a post-human aesthetic of video games.

More importantly, post-human play - most tangible in the case of automated gameplay - opens up to many other theoretical perspectives, which have the chance to surmount the mantra of interactivity: intra-activity (Barad 2003), interpassivity (Pfaller 1996, 2008; Žižek 1997) or aesthetics of ambience (Schröter et al. 2018), amongst many others. After all, at some point, many concepts and terms in media and games theory reach their end, and remain nothing more than empty clichés; interactivity being one of them (Zielinski 2014: 238). The term obstructs the full view of the video game and our relationship to it, and my aim in this article was to bring to light that which has been covered by it. 


\section{Acknowledgements}

This article is an aftermath of many academic thought-exchanges, conference panels and discussions I had the pleasure to experience, attend and run with numerous friends and colleagues. I would like to extend my thanks to: Anne Dippel, Justyna Stępień, Paolo Ruffino, Sebastian Möring, Seth Giddings, Justyna Janik, Markus Rautzenberg, Jan Stasieńko and Francesca Ferrando, among many others. Some of the ideas and concepts discussed in this article have appeared in different forms in earlier publications: 'Automated state of play. Rethinking anthropocentric rules of the game' (in Digital Culture and Society's special issue on Rethinking AI, October 2018) and 'Interpassivity and the joy of delegated play in idle games' (in Transactions of the Digital Games Research Association, April 2018, Volume vol. 3, no. 3).

\section{References}

Aarseth, Espen (1997), Cybertext: Perspectives on ergodic literature, Baltimore, MD: Johns Hopkins University Press.

Aarseth, Espen and Calleja, Gordon (2015), 'The Word Game: The ontology of an indefinable object', in Proceedings of the 10th International Conference on the Foundations of Digital Games (FDG 2015), 22-25 June 2015, Pacific Grove, CA, USA,

https://pdfs.semanticscholar.org/6c85/bdd2216a56e296cdc708af0480c4a20cd21c. pdf?.ga=2.77012053.1158569559.1501311498-1466169220.1501311498.

Accessed 13 July 2018. 
Aytes, Ayhan (2011), 'Cognitive labour, crowdsourcing, and cultural history of the mechanisation of the mind', Leonardo Electronic Almanac, 17:118-128.

BBC Newsnight (2016), 'AlphaGo and the future of artificial intelligence', YouTube, Retrieved 10 May 2017, https://www.youtube.com/watch?v=53YLZBSS0cc.

Bethesda Game Studios (2015), Fallout 4 [Microsoft Windows, PlayStation 4, Xbox One], Rockville, MD: Bethesda Softworks.

Blizzard Entertainment (2004), World of Warcraft [Microsoft Windows, macOS], Irvine, CA: Blizzard Entertainment.

Blizzard's statement (2015), 'Recent actions against botting in WoW', 13 May, Retrieved 17 May 2017, http://us.battle.net/forums/en/wow/topic/17347095985. Accessed 13 July 2018.

Barad, Karen (2003), 'Posthumanist performativity: Toward an understanding how matter comes to matter', Signs: Journal of Women in Culture and Society, 28:3, pp. 801-31.

Barrett, Brian (2017), 'Instead of banning cheaters, Pokemon Go trolls them hard', https://www.wired.com/2017/05/pokemon-go-cheaters-shadowban. Accessed_14 November 2017.

Björk, Staffan and Juul, Jesper (2012), 'Zero-Player games: Or what we talk about when we talk about player', paper presented at the Philosophy of Computer Games Conference, Madrid, Spain, January 29-31.

Bogost, Ian (2010), 'Cow clicker. The making of obsession', http://bogost.com/writing/blog/cow_clicker_1. Accessed 14 November 2017. 
_ (2012), Alien Phenomenology, or What It's Like to Be a Thing, Minneapolis, MN: The University of Minnesota Press.

(2017), 'The video game that claims everything is connected', The Atlantic,

March, https://www.theatlantic.com/technology/archive/2017/03/a-video-gameabout-everything/520518. Accessed 14 July 2018.

Braidotti, Rossi (2013), The Posthuman, Cambridge, UK: Polity Press.

Brewster, Kat (2017), Everything review: A joyfully expansive dream of a game', The Guardian, https://www.theguardian.com/technology/2017/mar/24/everythingreview-david-oreilly-game. Accessed 14 November 2017.

Caillois, Roger ([1958] 2001), Man, Play and Games, Chicago, IL: The University of Illinois Press.

Cheng, Ian (2017), Emissaries [Twitch.tv, MoMA PS1], Ian Cheng, New York, NY: MoMA PS1.

Cohen, John (1967), Human Robots in Myth and Science, Cranbury, New Jersey: A. S. Barnes and Co.

Crawford, Chris (1984), The Art of Computer Game Design, New York, NY: McGrawHill.

De Paoli, Stefano (2013), 'Automatic play and player deskilling in MMORPGs', Game Studies, 13:1, http://gamestudies.org/1301/articles/depaoli_automatic_play. 17 May 2017.

Deepmind, 'AlphaGo zero: Learning from scratch', https://deepmind.com/blog/alphagozero-learning-scratch. Accessed 1 August 2018. 
Deleuze, Gilles and Guattari, Felix ([1980] 1987), A Thousand Plateaus. Capitalism and Schizophrenia (trans. Brian Massumi), Minneapolis, MN and London: The University of Minnesota Press.

Dippel, Anne and Fizek, Sonia (2017), 'Playbouring cyborgs: Renegotiating the humanmachine ensembles', paper presented at the Annual Meeting of the Association of American Geographers (AAG), Digital / Human / Labour session, Boston, USA, April 5-9.

Dyer-Witheford, Nick (2015), Cyber-Proletariat. Global Labour in the Digital Vortex, Chicago, IL: University of Chicago Press.

Ermi, Laura and Mäyrä, Frans (2015), 'Fundamental components of the gameplay experience: Analysing immersion', in Proceedings of the Digital Games Research Association Conference (DiGRA 2005), Vancouver, Canada, 2005, pp. 15-27.

Ferrando, Francesca (2013), 'Posthumanism, transhumanism, antihumanism, metahumanism, and new materialisms. Differences and relations'. Existenz, An International Journal in Philosophy, Religion, Politics, and the Arts, 8:26-32.

_ (2018), 'Philosophical posthumanism', A talk at the 10th Beyond Humanism Conference, Wroclaw, Poland, 18 July.

Fizek, Sonia (2018a), 'Interpassivity and the joy of delegated play in idle games', Transactions of the Digital Games Research Association, 3:3, April, pp. 137-63. (2018b), 'Automated state of play. Rethinking anthropocentric rules of the game', special issue Rethinking AI, Digital Culture and Society, Berlin: De Gruyter. 
Frey, Benedikt Carl and Osborne, A. Michael (2013), 'The future of employment: How susceptible are jobs to computerisation?', Oxford Martin School, University of Oxford, Retrieved 17 May 2017, http://www.oxfordmartin.ox.ac.uk/downloads/academic/The_Future_of_Employ ment.pdf.

Galloway, Alexander R. (2006), Gaming. Essays on Algorithmic Culture, Minneapolis, MN and London: The University of Minnesota Press.

Gibbs, Samuel (2016), 'Google AI project writes poetry which could make a Vogon proud', The Guardian, 17 May, Retrieved 17 May 2017, https://www.theguardian.com/technology/2016/may/17/googles-ai-write-poetrystark-dramatic-vogons.

Giddings, Seth (2005), 'Playing with non-humans: Digital games as techno-cultural form', Proceedings of DiGRA 2005 Conference: Changing Views - World in Play, June 16-20, 2005, Vancouver, Canada http://www.digra.org/digitallibrary/publications/playing-with-non-humans-digital-games-as-techno-culturalform. Accessed 14 November 2017.

Hansen, B. N. Mike (2015), 'Symbolizing time: Kittler and twenty-first-century media', in S. Sale and L. Salisbury (eds), Kittler Now. Current Perspectives in Kittler Studies, Cambridge: Polity Press, 210-237.

Haraway, Donna ([1991] 2000), ‘A cyborg manifesto. Science, technology, and socialistfeminism in the late twentieth century', in D. Bell and B. M. Kennedy (eds), The Cybercultures Reader, London and New York: Routledge, pp. 291-324. 
Hayles, Katherine (2011), How We Think? Digital Media and Contemporary

Technogenesis, The University of Chicago Press.

Hyper Hippo Productions (2015), AdVenture Capitalist [iOS], Kongregate.

Hernandez, Patricia (2017), 'Pokémon go starts giving cheaters marks of shame',

https://kotaku.com/pokemon-go-starts-giving-cheaters-marks-of-shame-

1796297049. Accessed 17 November 2017.

Huizinga, Johan ([1938] 1992), Homo Ludens: A Study of the Play-Element in Culture,

Boston, MA: Beacon Press.

Jayemanne, Darshana (2017), Performativity in Art, Literature and Videogames,

Basingstoke, UK: Palgrave McMillan.

Julien Thiennot, (2013), Cookie Clicker [WW], Crazy Games.

Juul, Jesper (2003), 'The game, the player, the world: Looking for a heart of gameness',

in M. Copier and J. Raessens (eds), Proceedings of Digital Games Research

Conference (DiGRA 2003), Utrecht: Utrecht University, pp. 30-45.

Keogh, Brendan (2014), 'Cybernetic memory and the construction of the posthuman self in videogame play', in D. M. Weiss, A. D. Propen and C. E. Reid (eds), Design, Mediation, and the Posthuman, Lanham: Lexington Books, pp. 233-47.

Lantz, Frank (2017), Universal Paperclips [WW] Everybody House Games.

Lem, Stanisław (1983), 'Wielkie Lanie' ('The great spanking'), in S. Lem (ed.), Bajki

Robotów (Fables for Robots), Warszawa: Krajowa Agencja Wydawnicza

Warszawa Literackie., 179-187

Licklider, Joseph Carl Robnett (1960), 'Man-computer symbiosis', IRE Transactions on Human Factors in Electronics, HFE-1, March, pp. 4-11, 
http://worrydream.com/refs/Licklider\%20-\%20Man-Computer\%20Symbiosis.pdf. 17 May 2017.

Livingston, Christopher (2017), 'The sim settlements mod for fallout 4 is so good it should be an official part of the game', PC Gamer, http://www.pcgamer.com/the$\underline{\text { sim-settlements-mod-for-fallout-4-is-so-good-it-should-be-an-official-part-of-the- }}$ game. Accessed 16 November 2017.

Manovich, Lev (2001), The Language of New Media, Cambridge, MA: The MIT Press. Mateas, Michael (1999), 'An Oz-centric review of interactive drama and believable agents', in M. Wooldridge and M. Veloso (eds), AI Today: Recent Trends and Developments, Springer, pp. 297-328.

McAfee, Andrew and Brynjolfsson, Erik (2011), 'Race against the Machine. How the Digital Revolution is Accelerating Innovation, Driving Productivity, and Irreversibly Transforming Employment and the Economy', Lexington, MA: Digital Frontier Press.

Mukherjee, Souvik (2008), 'Gameplay in the "zone of becoming". Locating action in the computer game', in S. Gunzel, M. Liebe and D. Mersch (ed.), Conference Proceedings of the Philosophy of Computer Games, Potsdam University Press, pp. $228-41$.

Nake, Frieder (1971), 'There should be no computer art', Bulletin of the Computer Arts Society, Birkbeck, University of London, pp. 18-21, http://www.bbk.ac.uk/hosted/cache/archive/PAGE/PAGE18.pdf. Accessed 17 May 2017. 
Neumann, John von (1966), Theory of Self-Reproducing Automata (ed. Arthur W.

Burks), Urbana, IL and London: University of Illinois Press.

Niantic (2016), Pokémon Go [iOS, Android], Pokémon Company Nintendo.

Observations on the Automaton Chess Player (1819), Now Exhibited in London at 4.

Spring Gardens. By an Oxford Graduate, London: Printed for J. Hatchard.

OReilly, David (2017), Everything [PlayStation 4], Double Fine Productions.

Pfaller, Robert (1996), 'Um Die Ecke Gelacht', Falter, 41/96, p. 71.

_ (2008), Ästhetik der Interpassivität, Hamburg: Fundus, Philo Fine Arts.

Richter, Jean Paul (1795), 'Menschen sind Maschinen der Engel',

http://www.salmoxisbote.de/Bote01/Paul.htm. Accessed 14 November 2017.

Riskin, Jessica (2003), The Defecating Duck, or, the Ambiguous Origins of the Artificial

Life, Chicago, IL: University of Chicago Press.

Rossignol, Jim (2012), 'Idle musings. Watching the AI fight', Rock Paper Shotgun, https://www.rockpapershotgun.com/2012/03/02/idle-musing-watching-the-aifight. 20 November 2017.

Salen, Katie and Zimmerman, Eric (2003), Rules of Play: Game Design Fundamentals, Cambridge, MA: The MIT Press.

Schröter, Jens, Schwering, Gregor, Maeder, Dominik and Heilmann, Till A. (eds) (2018), Ambient. Ästhetik des Hintergrunds, Springer.

Silver, David et al. (2017), 'Mastering the game of go without human knowledge', Springer Nature, 550, pp. 354-72, https://www.nature.com/articles/nature24270.epdf. Accessed 1 August 2018. 
Stasieńko, Jan (2017), ‘Automaty, hybrydy, afekty - posthumanistyczne konteksty apartu gry komputerowej i praktyk grania', Teksty Drugie, 3.1.

Truitt, Elly R. (2015), Medieval Robots. Mechanism, Magic, Nature and Art, Pittsburgh, PA: University of Pennsylvania Press.

Voskuhl, Adelheid (2013), Androids in the Enlightenment. Mechanics, Artisans, and Cultures of the Self, The University of Chicago Press.

Wark, McKenzie (2009), Gamer Theory, Cambridge, MA: Harvard University Press.

Wiener, Norbert (1948), Cybernetics: Or Control and Communication in the Animal and the Machine, Cambridge, MA: The MIT Press.

Zielinski, Siegfried (2014), “Past is an infinite set of possibilities”: Siegfried Zielinski in conversation on anarcheology of media', Teksty Drugie (Second Texts Journal), 3, pp. 227-42. Warsaw: IBL PAN.

Žižek, Slavoj (1997), The Plague of Fantasies, London: Verso. 